\title{
RF MEMS SWITCHES USING COPPER-BASED CMOS INTERCONNECT MANUFACTURING TECHNOLOGY
}

\author{
N. Hoivik, C. V. Jahnes, J. Cotte, J. L. Lund ${ }^{1}$, D. Seeger and J. H. Magerlein \\ IBM T. J. Watson Research Center, PO Box 218, Yorktown Heights, NY 10598, USA \\ ${ }^{1}$ Current address: 22822 Howard Chapel Road, Brookeville, MD 20833, USA
}

\begin{abstract}
High-quality RF MEMS switches fabricated using a Cubased integrated circuit interconnect technology have been demonstrated. The process technology allows the fabrication of switches within the interconnect layers of an RF integrated circuit for low packaged cost and superior performance, The switch design includes a beam fixed at both ends and actuation electrodes separate from the RF conductors. Switch isolation is better than $30 \mathrm{~dB}$ from $0-6 \mathrm{GHz}$, insertion loss is $0.3 \mathrm{~dB}$, and actuation voltage is about $26 \mathrm{~V}$ for a switch with a gap of 0.2 $\mu \mathrm{m}$. Optimizing switch performance requires careful attention to film stress.
\end{abstract}

\section{INTRODUCTION}

In a large number of RF applications, the many discrete, board-level components significantly increase assembly cost and overall size, as well as limiting performance. Thus integrated passive components would be desirable [1]. It is well recognized that RF-MEMS switches have been shown to exhibit superior performance compared to FET and diode switches; however most of these devices have been built using highly special processing techniques incompatible with integrated circuit fabrication. As a result, the implementation of RF MEMS devices into products has remained elusive [2].

This paper describes the first high-quality switches fabricated using a copper-based integrated circuit interconnect technology. The objective is to develop integrated switches for 2 $\mathrm{GHz}$ applications using standard "back-end" processing compatible with Bi-CMOS or SiGe technology [3], [4].

Typical RF design specifications for an integrated switch are presented in Table 1. The isolation required in the OFF state is more than $30 \mathrm{~dB}$; while the insertion loss in the $\mathrm{ON}$ state should be less than $0.5 \mathrm{~dB}$.

\begin{tabular}{|l|c|}
\hline \multicolumn{2}{|c|}{ RF Performance @ $2 \mathrm{GHz}$} \\
\hline Isolation & $>30 \mathrm{~dB}$ \\
Insertion loss & $<0.5 \mathrm{~dB}$ \\
Actuation voltage & $<10-15 \mathrm{~V}$ \\
Switching speed & $10-100 \mu \mathrm{sec}$ \\
Power handling & $10-100 \mathrm{~mW}$ \\
\hline
\end{tabular}

Table 1: Typical specifications for integrated MEMS switch

\section{SWITCH FABRICATION AND DESIGN}

The integrated MEMS switch is fabricated using a conventional back-end copper based CMP (Chemical Mechanical Polishing) process. All of the dielectric and metal films are deposited at temperatures of $400^{\circ} \mathrm{C}$ or less using tools and processes typically used in CMOS processing. The MEMS structures are released using a dry release process [4].

Using a copper-based process to create free-standing MEMS devices adds to the complexity of the MEMS device. In order to prevent the copper from oxidizing, the metal structure must be encapsulated to prevent corrosion during processing. Therefore, the resulting micromechanical beam tends to have a complicated multilayer cross-section, and film stresses must be considered during fabrication to avoid overall compressive beam stress and severe stress gradients.

Figure 1 depicts a top-view photograph of a fabricated and released, MEMS switch. The two actuation electrodes are kept separate from the RF conductor (in center). The switch measures $24 \mathrm{x}$ $105 \mu \mathrm{m}$, with a $2 \mu \mathrm{m}$ space separating the actuation electrodes from the RF conductor.

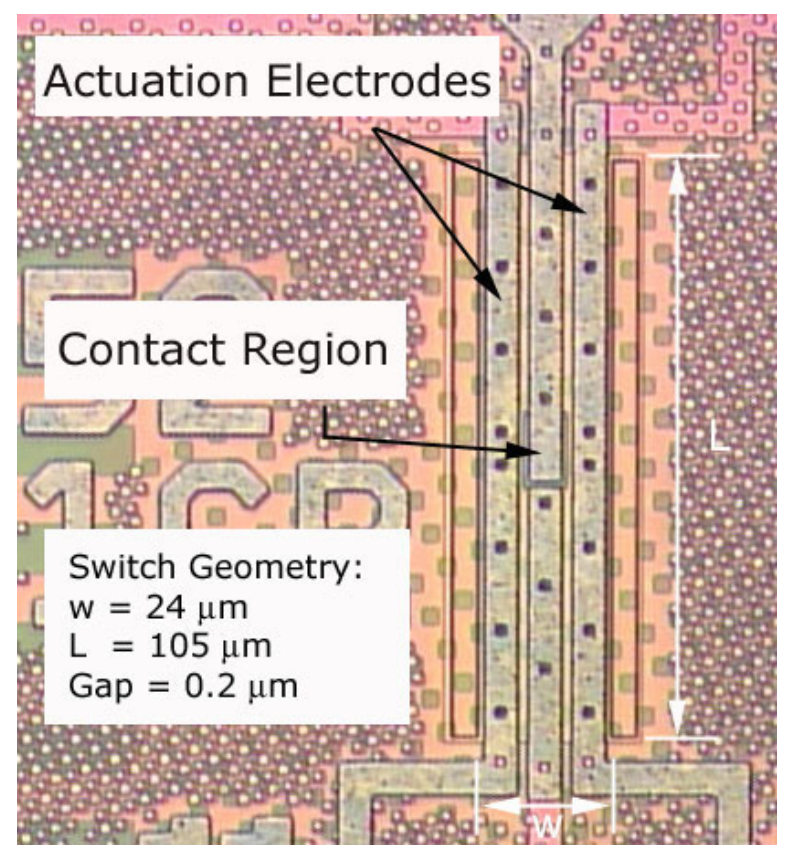

Figure 1: Top-view photograph of fabricated RF MEMS switch. The two actuation electrodes are separated from the $R F$ conductor and contact region in the center of the bridge structure. 
Figure 2 illustrates a side-view of the RF-MEMS switch. The switch is fixed at both ends to ensure an adequate restoring force compared to a cantilever design. However, the RF conductor only covers half of the suspended length to mimic a series cantilever switch. In order to balance stresses due to the mismatch between copper and dielectric materials, the bridge incorporates a "dummy" metal region. Furthermore, the upper contact region consists of several smaller contacts (18 contacts of $1 \mathrm{x} 1 \mu \mathrm{m}$ in $\mathrm{C} 2$ ), whereas the lower contact (C1) is a uniform contact region. Having the contact material formed in patches on the upper contact facilitates a larger contact force when the switch is actuated. Etch holes along the actuation electrodes and RF conductor both facilitates an improved release process as well as reducing squeeze film damping when operated in a $\mathrm{N}_{2}$ environment.

The gap between the two actuation electrodes was designed to be $0.2 \mu \mathrm{m}$ in order to obtain a low actuation voltage, while at the same time allow the switch to demonstrate an adequate isolation at the design frequency of $2 \mathrm{GHz}$.

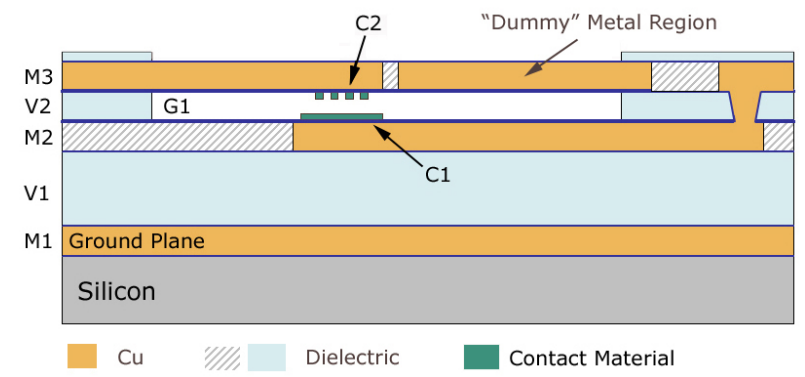

Figure 2: Side-view schematic of the MEMS switch. The switch is anchored on both ends with a dummy metal region to balance stress. The upper contacts (C2) consist of 18 small (1x1 $\mu \mathrm{m})$ contacts whereas the lower contact (C1) is uniform.

\section{RESULTS AND DISCUSSION}

All RF measurements were performed on wafer level in a controlled nitrogen environment. Microwave probes and an HP8753B network analyzer were used. The measured performance of the RF MEMS switch is presented in Figure 3. The measured isolation in OFF state was measured to be greater than $30 \mathrm{~dB}$ from $\mathrm{DC}$ to $6 \mathrm{GHz}$, corresponding to an up state capacitance about $6.5 \mathrm{pF}$, which also matches simulated values. The actuation voltage required to make initial contact was measured to be around $12-15 \mathrm{~V}$, however $24 \mathrm{~V}$ was required to obtain an insertion loss of $0.3 \mathrm{~dB}$. This actuation voltage was measured on repeated devices and no further reduction on insertion loss was observed up to $30 \mathrm{~V}$, which indicates that a proper contact was made.

Further simulation of the MEMS switch indicated a deformation in the actuation electrodes around $0.15 \mu \mathrm{m}$ (Figure 4). This deformation is not unexpected due to the nature of a multi-layer beam. However, the magnitude of stress was somewhat larger than expected, thus with a deformation on the order of the design gap separating the two electrodes, the actuation voltage would greatly be increased.

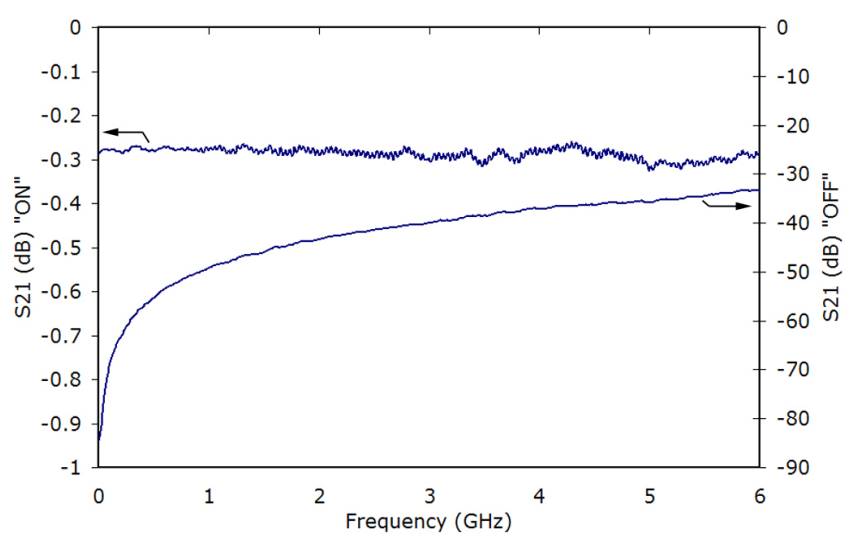

Figure 3: Measured S21 transmission of MEMS switch with $+10 \mathrm{dBm}$ power and using response calibration. The actuation voltage is $24 \mathrm{~V}$.

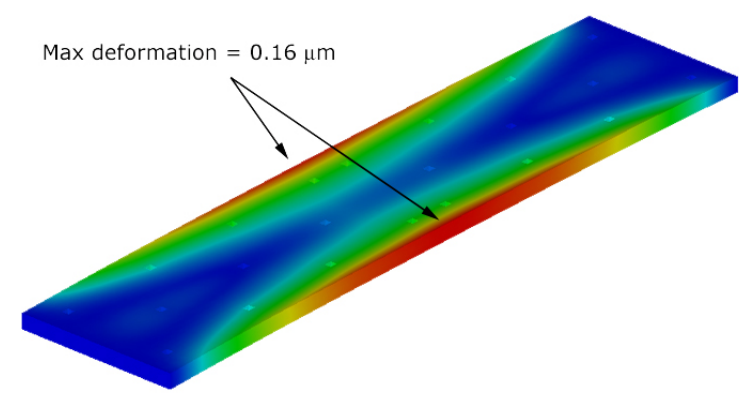

Figure 4: Simulation of deformation in switch actuation electrodes due to a high stress gradient in the multilayer stack.

\section{SUMMARY}

This paper describes an RF MEMS switch fabricated with a $\mathrm{Cu}$ CMP process suitable for direct integration with $\mathrm{SiGe}$ or Bi-CMOS IC's. A "direct integration" approach demonstrates the potential for a MEMS device to share existing mask levels, thus diluting the cost of the MEMS device into the base cost.

The measured RF performance is well within the initial specifications. Further reduction in stress is currently under investigation together with measurements of switching speed, reliability and power handling.

\section{REFERENCES}

1. D. Seeger et al. "Fabrication Challenges for next-generation devices: Microelectromechanical systems for radio-frequency wireless communications," J. Microlith., Microfab., Microsyst., Vol. 2 No. 3, pp 169 177 (2003).

2. $\quad$ Arthur S. Morris et al, "High-Performance Integrated RF-MEMS: Part 1- The Process", 11th GAAS Symposium - Munich 2003, pp 325 - 328.

3. Jennifer L. Lund et al,"A Low Temperature Bi-CMOS Compatible Process for MEMS rf Resonators and Filters". Solid-State Sensor, Actuator and Microsystems Workshop, Hilton Head Island, June 2-6, 2002.

4. C. V. Jahnes et al. " Simultaneous Fabrication of RF MEMS Switches and Resonators using Copper-based CMOS Interconnect Manufacturing Methods", MEMS 2004 Technical Digest, Jan 25-29, pp 789 - 792. 